\title{
Breast Cancer Survival in Cameroon: Analysis of a Cohort of 404 Patients at the Yaoundé General Hospital
}

\author{
Jean Dupont Kemfang Ngowa ${ }^{1,2}$, Jean Marie Kasia, ${ }^{1,2}$, Jean Yomi' ${ }^{3}$, Achille Nkigoum Nana ${ }^{1}$, \\ Anny Ngassam1, Irenée Domkam ${ }^{4}$, Zacharie Sando ${ }^{5}$, Paul Ndom ${ }^{6}$ \\ ${ }^{1}$ Department of Gynecology and Obstetrics, Yaoundé General Hospital, Faculty of Medicine and Biomedical \\ Sciences, University of Yaounde I, Yaoundé, Cameroon \\ ${ }^{2}$ Obstetrics and Gynecology Unit, Yaoundé General Hospital, Yaoundé, Cameroon \\ ${ }^{3}$ Department of Radiation Therapy, Yaoundé General Hospital, Faculty of Medicine and Biomedical Sciences, \\ University of Yaoundé I, Yaoundé, Cameroon \\ ${ }^{4}$ Chantal Biya International Reference Centre for Research on HIV/AIDS Prevention and Management, Yaoundé, \\ Cameroon \\ ${ }^{5}$ Department of Morphological Sciences, Yaoundé General Hospital, Faculty of Medicine and Biomedical \\ Sciences, University of Yaoundé I, Yaoundé, Cameroon \\ ${ }^{6}$ Oncology Division, Yaoundé General Hospital, Yaoundé, Cameroon \\ Email: jdkemfang@yahoo.fr
}

Received 25 February 2015; accepted 27 March 2015; published 30 March 2015

Copyright @ 2015 by authors and Scientific Research Publishing Inc.

This work is licensed under the Creative Commons Attribution International License (CC BY).

http://creativecommons.org/licenses/by/4.0/

(c) (i) Open Access

\section{Abstract}

This study aimed to estimate the survival rate of breast cancer in a group of patients followed up at the Yaoundé General Hospital in Cameroon. A retrospective review of records of patients managed for breast cancer between 1995 and 2007 was carried out at the Yaoundé General Hospital. Survival analysis was carried out with survival defined as the time between the date of unequivocal diagnosis of cancer and the date of last follow-up or death. Survival curves were plotted in R.3.1.1 software. Mean age of the patients was $47.5 \pm 12.36$ years. Most of the patients $(67.9 \%)$ presented with advanced breast cancer disease (stage III and IV). Overall patient survival rate was $30 \%$ at 5 years and $13.2 \%$ at 10 years. Median overall survival time was $2(1.9-3)$ years. There was a correlation between survival and the stage of disease. The highest survival rates were recorded in stages I and II while the lowest rates were recorded in stage IV. There was no statistically significant difference in survival among the age groups $(p=0.15)$. Overall survival rates of breast cancer are $30 \%$ at 5 years and $13.2 \%$ at 10 years among Cameroonian patients and are lower compared with $90 \%$ and $82 \%$ respectively at 5 years and 10 years in some developed countries.

How to cite this paper: Ngowa, J.D.K., Kasia, J.M., Yomi, J., Nana, A.N., Ngassam, A., Domkam, I., Sando, Z. and Ndom, P. (2015) Breast Cancer Survival in Cameroon: Analysis of a Cohort of 404 Patients at the Yaoundé General Hospital. Advances in Breast Cancer Research, 4, 44-52. http://dx.doi.org/10.4236/abcr.2015.42005 


\section{Keywords}

\section{Survival, Breast Cancer, Developing Countries}

\section{Introduction}

Breast cancer is now the most frequent cancer of women worldwide with up to a million cases occurring annually [1]. In Cameroon, according to the Globocan 2010 estimation, breast cancer is the most frequent cancer in women before cervical cancer with an incidence of 27.9 per 100,000 women [2].

Lifestyle changes associated with urbanization and the concomitant loss of traditional protective factors appear to be associated with the rising incidence of breast cancer in African women [3] [4].

Although more than half of all new cases of breast cancer are diagnosed in the industrialized world (i.e. North America excluding Mexico and Western Europe), more than three quarters of breast cancer related deaths occur in the developing countries. This discordance in incidence and survival is largely related to the lack of organized mammographic screening in developing countries, the advanced stage at diagnosis $(>60 \%$ of patients are diagnosed with stage III/IV breast cancer in the developing countries), poor access to care, and substandard treatment regimens [4]-[7].

Population-based survival represents the average prognosis of a cancer and is useful for assessing progress in cancer control, including the effect of early detection, diagnosis, treatment, and follow-up on cancer outcomes. The data are also helpful in making informed decisions to ensure improved and equitable cancer care [8].

Cancer survival statistics from developing countries are rare. The reasons for the paucity of information about cancer survival from developing countries are readily understandable. Cancer registries are a recent phenomenon in some developing countries, and do not exist at all in many others. Death registration in developing countries is often incomplete, not all deaths are registered, and the recorded cause of death may be inaccurate, or missing [9].

This study aimed to estimate the survival of a group of breast cancer patients followed up at the Yaoundé General Hospital (YGH) in Cameroon.

\section{Patients and Methods}

This was a retrospective study in which the medical records of breast cancer patients treated at the YGH between January 1995 and December 2007 were used. The end of the observation period of survival was the 31st of December 2013.

The YGH is one of the most specialized hospitals in the treatment of cancer in Cameroon. It has a number of services specialized in the treatment of cancers such as radiotherapy, medical oncology, anatomic pathology, nuclear medicine, gynecology and surgery. Breast cancer patients followed up at the YGH were most often referred from other health facilities and came from all parts of the country. The breast cancer treatment options offered in this institution are: radical mastectomy and breast conserving surgery; adjuvant and neoadjuvant chemotherapy with the use of the drug combination CAF (Cyclophosphamide: $500 \mathrm{mg} / \mathrm{m}^{2}$, Adriamycin: 50 $\mathrm{mg} / \mathrm{m}^{2}, 5$-fluorouracil: $500 \mathrm{mg} / \mathrm{m}^{2}$ ) every 21 days for 6 cycles; hormone therapy with Tamoxifen and radiotherapy delivered by a cobalt unit at the dose of 50 Gy over 5 weeks for post-mastectomy patients when indicated. However, in the case of breast conserving treatment, a dose of 50 Gy over 5 weeks with a boost dose of $15 \mathrm{~Gy}$ to the tumor site is administered.

Out of the 404 breast cancer patients registered in the YGH during the study period, 221 (54.75\%) were included in our study. The patients excluded were those whose medical records were not found (139 cases) and those with no follow-up after diagnosis of breast cancer (44 cases).

The survival status of patients within 5 years or 10 years from the date of unequivocal diagnosis of cancer was obtained by active and passive methods. The passive assessment method of survival was based on medical records. Survival was calculated as the time between the date of diagnosis of cancer and the date of death from any cause or the date of loss to follow up or the date of last follow-up. The active measure undertaken to establish the survival status of patients without death information in their medical records was to contact the patient or their relatives by phone. The endpoint in this study was death, regardless of the cause. The socio-demographic 
information, disease characteristics and vital status of patients were collected.

Global and specific (by age, stage of disease, and treatment modalities) survival curves were estimated via the actuarial method. The equality of these curves was tested using a log-rank test. Analysis was done using R v3.1.0 (Statistical analysis system, GNU GPL).

\section{Results}

Between January 1995 and December 2007, 404 breast cancer patients were followed at the YGH. Of these, 221 patients who had a medical record found in the archives were included in this study. The socio-demographic characteristics of the patients are shown in Table 1. The mean age of the patients was $47.5 \pm 12.36$ years. The most represented age group was 40 - 49 years. Slightly more than half $(56.10 \%)$ of the study population lived in rural areas and $51.13 \%$ of the patients were housewives.

Table 2 shows the clinical and histopathological aspects of breast cancer in the study population.

Consultation for the symptoms presented by the patient was the circumstance of breast cancer discovery in $61 \%$ of cases and screening mammography was the circumstance of discovery only in $9.5 \%$ of cases.

Invasive ductal carcinoma was the most represented histological type of breast cancer (79.63\%) while invasive lobular carcinoma was found in $4.52 \%$ of cases. About the various treatment modalities in this study; $64.70 \%$ of patients underwent a radical mastectomy; $53.39 \%$ had neoadjuvant chemotherapy; $35.71 \%$ had adjuvant chemotherapy; $77.42 \%$ had radiotherapy and $19.0 \%$ had hormone therapy.

Table 1. Socio-demographic characteristics of breast cancer patients.

\begin{tabular}{|c|c|}
\hline Variables & Patients $n=221 n(\%)$ \\
\hline \multicolumn{2}{|c|}{ Age groups (years) } \\
\hline $20-30 y$ & $10(4.5)$ \\
\hline $30-39 y$ & $53(24)$ \\
\hline $40-49 y$ & $65(29.4)$ \\
\hline$\geq 50 \mathrm{y}$ & $93(42.1)$ \\
\hline \multicolumn{2}{|c|}{ Marital status } \\
\hline Married & $83(37.55)$ \\
\hline Single & $34(15.38)$ \\
\hline Widow & $12(5.42)$ \\
\hline unknown & $92(41.62)$ \\
\hline \multicolumn{2}{|l|}{ Profession } \\
\hline Employed & $97(43.89)$ \\
\hline Housewife & $113(51.13)$ \\
\hline Unknown & $11(04.97)$ \\
\hline \multicolumn{2}{|c|}{ Residential area } \\
\hline Urban & $92(41.62)$ \\
\hline Rural & $124(56.10)$ \\
\hline \multicolumn{2}{|l|}{ Religion } \\
\hline Christian & $115(52.03)$ \\
\hline Muslim & $14(06.33)$ \\
\hline Others & $15(06.78)$ \\
\hline Unknown & $77(34.84)$ \\
\hline
\end{tabular}


Table 2. Clinical and histopathological aspects of breast cancer in the study population.

\begin{tabular}{|c|c|}
\hline Variables & Patients $n=221$ n (\%) \\
\hline \multicolumn{2}{|c|}{ Circumstance of breast cancer discovery } \\
\hline Breast symptoms & $135(61.08)$ \\
\hline Clinical breast examination & $65(29.41)$ \\
\hline Mammography screening & $21(9.50)$ \\
\hline \multicolumn{2}{|l|}{ Stage of breast cancer } \\
\hline Stage I & $4(1.8)$ \\
\hline Stage II & $60(27.14)$ \\
\hline Stage III & $123(55.65)$ \\
\hline Stage IV & $27(12.21)$ \\
\hline Unknown stage & $7(3.16)$ \\
\hline \multicolumn{2}{|l|}{ Histological subtype } \\
\hline Ductal invasive carcinoma & $176(79.63)$ \\
\hline Ductal in situ carcinoma & $1(0.45)$ \\
\hline Lobular invasive carcinoma & $10(04.52)$ \\
\hline Adenocarcinoma & $23(10.40)$ \\
\hline Others & $11(4.97)$ \\
\hline \multicolumn{2}{|l|}{ Therapeutic modalities } \\
\hline Radical mastectomy & $143(64.70)$ \\
\hline Breast conserving surgery & $38(17.19)$ \\
\hline Neo adjuvant chemotherapy & $118(53.39)$ \\
\hline Adjuvant chemotherapy & $79(35.74)$ \\
\hline Radiotherapy & $172(77.82)$ \\
\hline Hormone therapy & $44(19.90)$ \\
\hline
\end{tabular}

Figure 1 shows the overall survival curves for breast cancer over a period of 10 years. The overall median survival was $2(1.9-3)$ years. Overall survival was $30 \%$ at 5 years and $13.2 \%$ at 10 years.

The specific survival curve according to the stage of disease is shown in Figure 2. The median survival was 5 (2.6 - 7.3) years at stage II; $3(2.3-3.6)$ years at stage III and $1(0.5-1.4)$ year at stage IV. All 4 patients in stage I were alive at the end of the observation period. There was a correlation between survival and the stage of disease. The highest survival rates were recorded in stages I and II and the lowest in stage IV. Furthermore, the difference between the survival curves at different stages of the disease was statistically significant $(p<0.001)$.

Figure 3 shows the survival curves for breast cancer with respect to age groups. There was no significant difference between these curves $(\mathrm{p}=0.15)$.

Figure 4 shows the survival curves with respect to the type of surgery (Figure 4(a)) and treatment with radiotherapy or not (Figure 4(b)).

The median survival was $6(2.8-9.1)$ years in patients who underwent breast conserving surgery and $2(1.3$ 2.6) years for those who underwent radical mastectomy. Survival was significantly higher $(p=0.01)$ in the group of patients who underwent breast conserving surgery compared to those who underwent radical mastectomy.

On the other hand, there was no significant difference in survival $(p=0.9)$ between breast cancer patients who received radiotherapy and those who did not (Figure 4(b)). The median survival was $2(1.4-2.5)$ years for patients who had radiotherapy and $2(0.7-3.2)$ years for those who did not. 


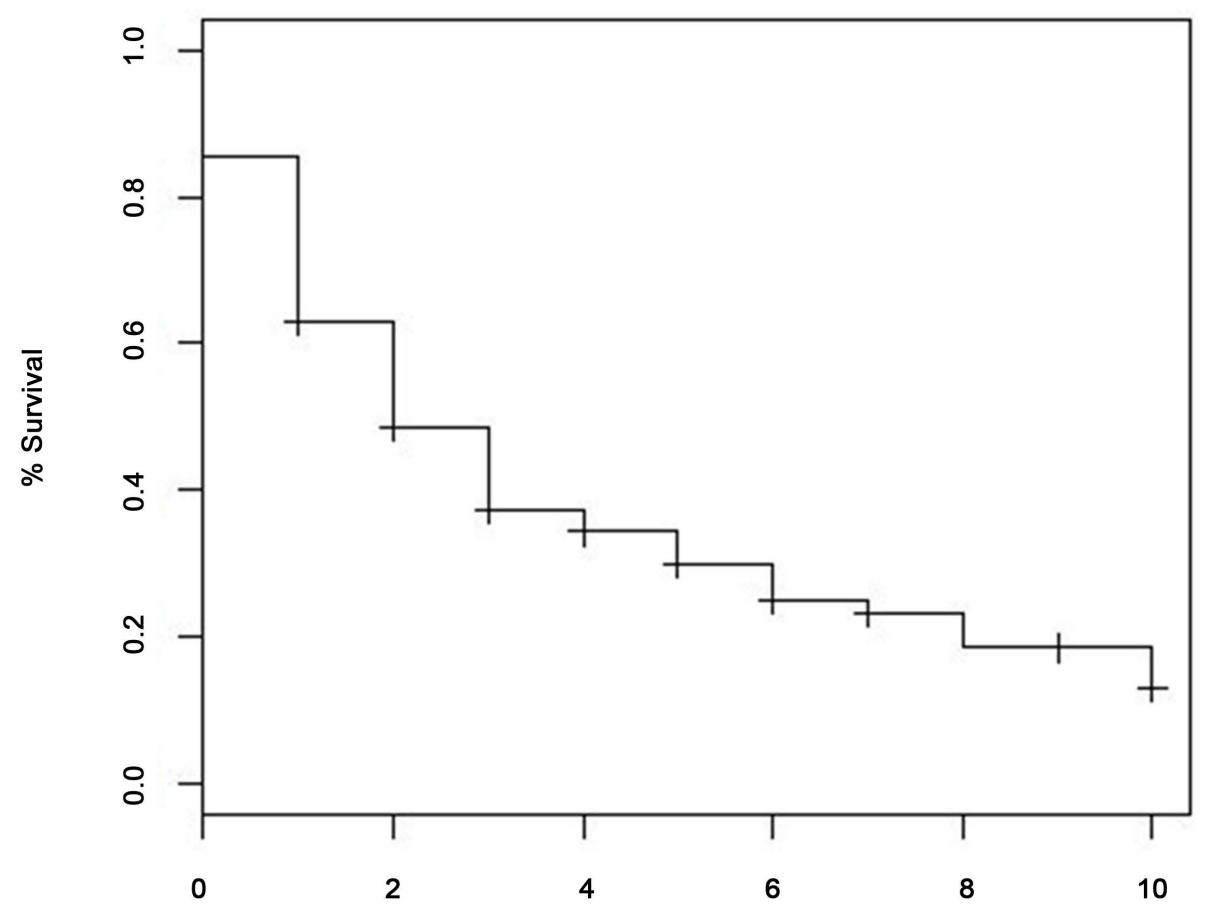

Years

Figure 1. Overall survival curves for breast cancer over a period of 10 years.

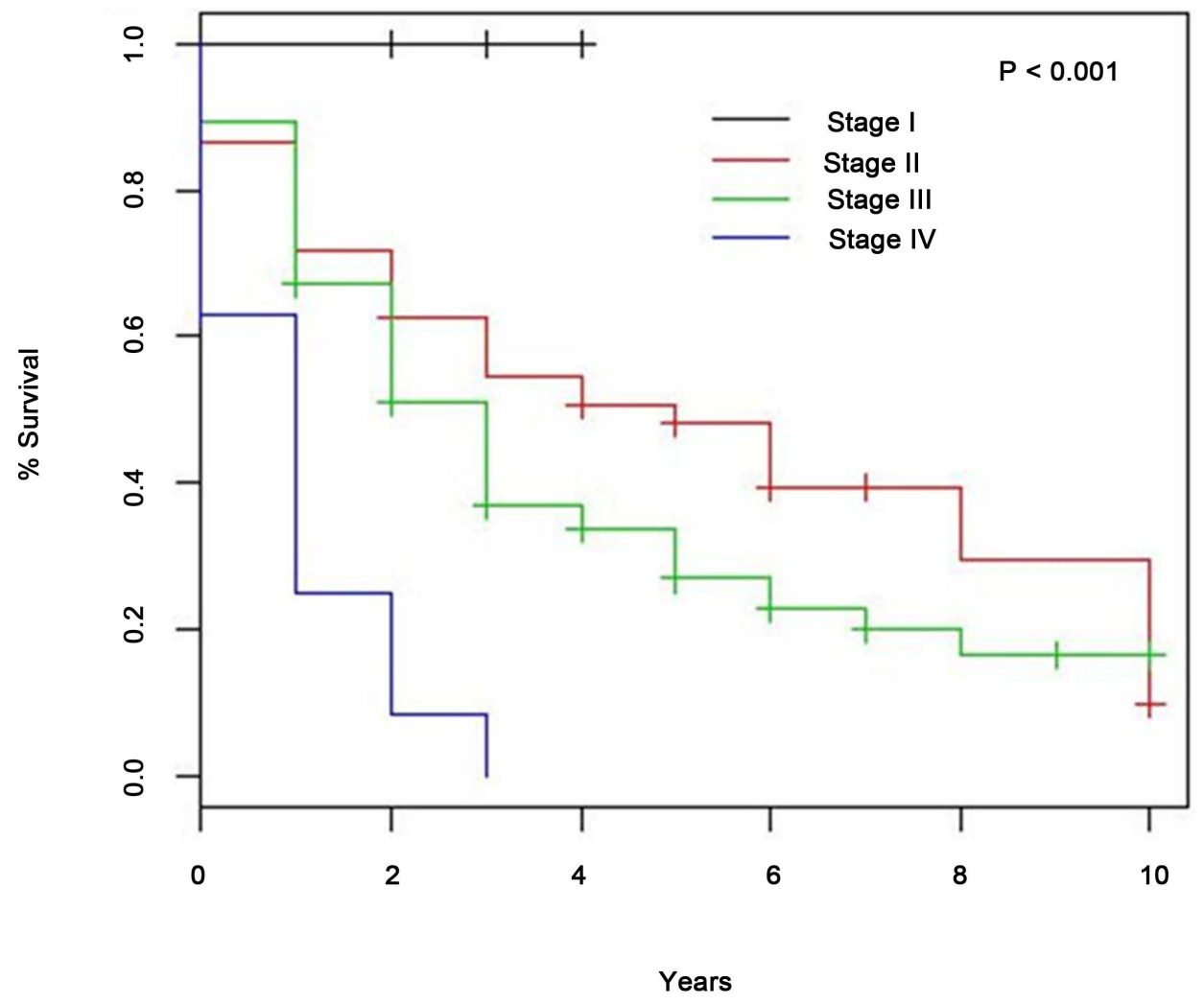

Figure 2. Specific survival curves according to the stage of disease. 


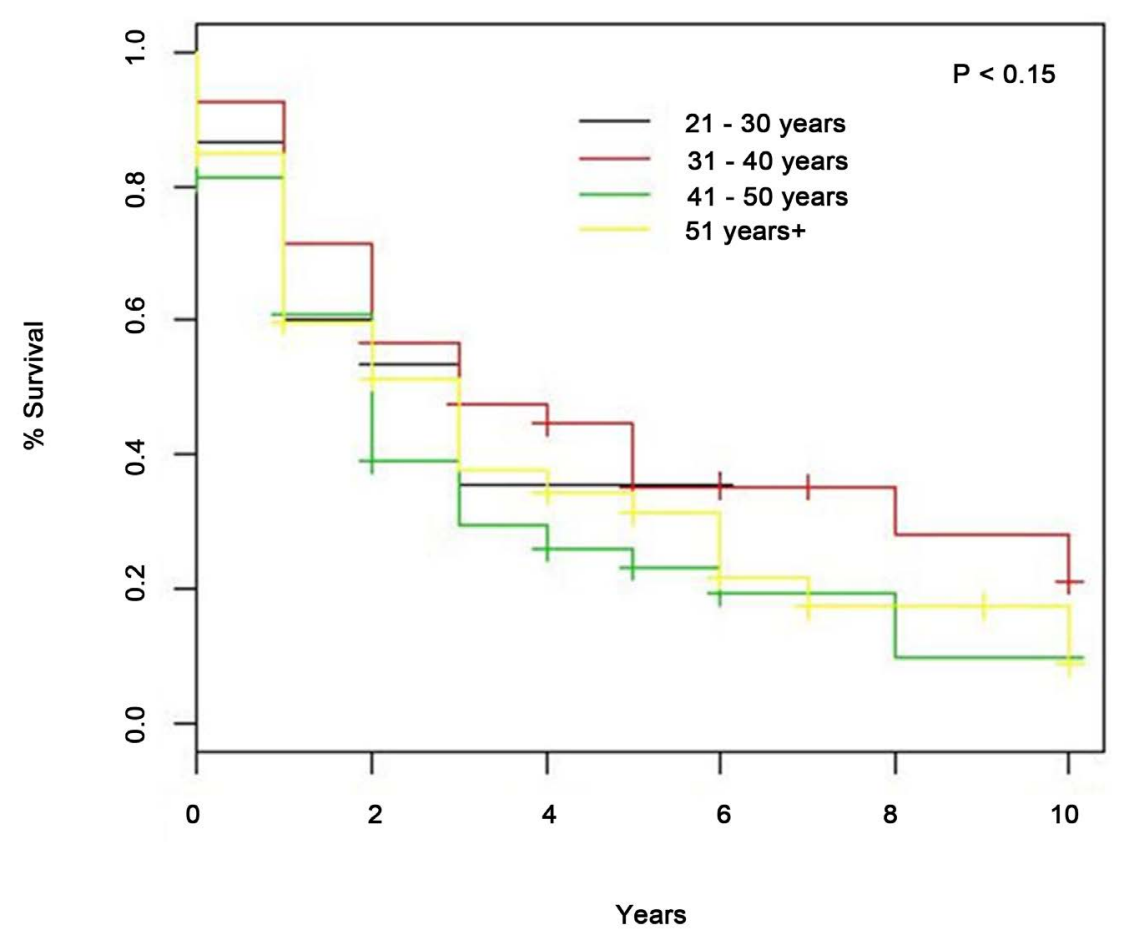

Figure 3. Survival curves for breast cancer with respect to age groups.

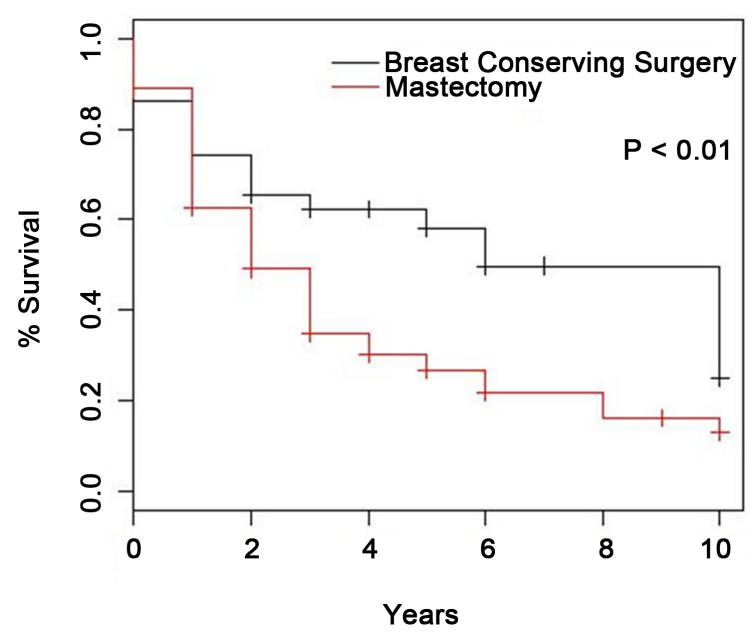

(a)

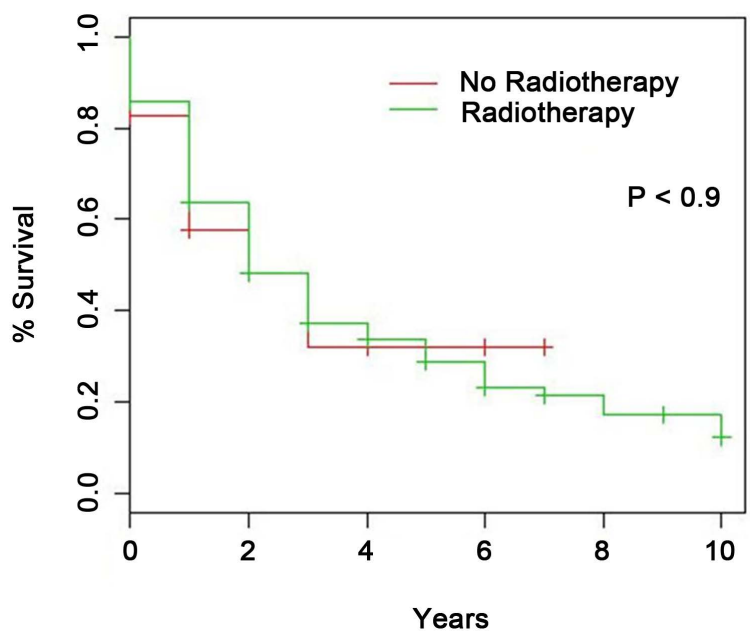

(b)

Figure 4. (a) Survival curves with respect to the type of surgery; (b) Survival curves with respect to the treatment with radiotherapy or not.

\section{Discussion}

Breast cancer management is a major challenge to physicians in developing countries [7]. As seen with many other developing countries, reliable data on survival following breast cancer management in Cameroon is lacking.

This study based on a cohort of breast cancer patients followed up at the Yaoundé General Hospital (YGH) in Cameroon revealed that, the overall survival rate at 5 years and 10 years were respectively $30 \%$ and $13.2 \%$. Our results are worse when compared to the survival rate of breast cancer patients managed in developed countries which are $90 \%$ and $82 \%$ at 5 years and 10years respectively in the USA and $84 \%$ at 5years in France [10], [11]. This worse outcome of breast cancer patients in Cameroon is similar to that reported in Nigeria (25.6\%), Tunisia 
(50.5\%), Uganda (46\%) and Gambia (12\%) at 5 years [8] [12] [13].

The poor survival from breast cancer in the developing countries when compared to some developed countries has been suggested to be related to the advanced stage at diagnosis and limited availability of adequate staging and therapy [3]. The later stage of disease at diagnosis in developing countries could be due to multiple factors like poverty, lack of screening programs low accessibility to diagnostic facilities, cultural beliefs constituting a barrier to early presentation [3]. The late stage of breast cancer (stage III, IV) represented $68 \%$ in this study confirming the data in the literature [12] [14]-[17].

Furthermore, the molecular and genetic differences in breast cancer may also contribute to geographic variations in survival. Insufficient data are currently available to define possible trends in different regions of the world [3]. In Cameroon, as in other developing countries, hormone receptors; HER2, p53, Ki 67 and BRCA1/ BRCA2 expression could not be tested during the study period.

Overall survival varies according to the stage of breast cancer. Patients diagnosed with stage 0 , I or II breast cancers tend to have higher overall survival rates than patients diagnosed with stage III or IV breast cancers [18].

Our results are similar to that of literature [18]. We observed a significant difference in survival between the different stages of breast cancer with the best survival being at stage I and II while the worse was at stage IV.

Breast cancer in young women compared to older women of 50 years and above is associated with a decreased survival [19]. As was seen in the study of Ben Gobrane et al. [20] at the Oncological Institute Salah Azaiez of Tunis, we found no significant difference in survival between the different age groups in our study. This could be due to a high proportion of advanced stage breast cancer in our study population which worsened the outcome, and to the low life expectancy in developing countries which could reduce considerably the survival of elderly women over 50 years. Internationally validated guidelines recommend adjuvant radiotherapy after breast conserving surgery and for patients with certain risk factors (T3/T4 or multicentricity) after mastectomy [21]. This strongly affects locoregional disease recurrence but has demonstrated a limited effect on long term survival [21]-[23].

In this study, there was no difference in survival between patients who underwent radiotherapy and those who did not probably due to high prevalence of advanced stage breast cancer.

Breast conserving surgery followed by adjuvant radiotherapy is an equivalent alternative to mastectomy for selected patients [22] [24] [25]. We found in this study significantly higher survival among patients who had breast conserving surgery when compared to those who had radical mastectomy. The difference in survival in these two groups could be due to the fact that breast conserving surgery is usually indicated for early breast cancer in contrast to mastectomy whose indications also include advanced stage disease.

The high proportion of loss to follow up because of unrecovered medical records is the main limitation of this study. This difficulty of archiving is very frequent in our hospitals and is a major challenge for research in developing countries. However, the results of this study provide an idea on breast cancer survival in our environment.

\section{Conclusion}

The overall survival rates of breast cancer are $30 \%$ at 5 years and $13.2 \%$ at 10 years among Cameroonian patients and are lower compared with $90 \%$ and $82 \%$ respectively at 5years and $10 y e a r s$ in some developed countries [11]. Consistent to the literature, survival rates to the breast cancer in our study were correlated to stages of disease. These results challenge us to improve breast cancer care in our environment and especially to implement the breast cancer screening programs in our community in order to reduce the stage of disease at diagnosis. However, educational campaigns will be a first step because early detection cannot be successful if the population is unaware of the problem or has adverse misconceptions about the value of early detection.

\section{Conflict of Interests}

The authors declare that there is no conflict of interests regarding the publication of this paper.

\section{References}

[1] Parkin, D.M., Bray, F., Ferlay, J. and Pisani, P. (2005) Global Cancer Statistics, 2002. CA: A Cancer Journal for Clini- 
cians, 55, 74-108. http://dx.doi.org/10.3322/canjclin.55.2.74

[2] International Agency for Research on Cancer (2010) Globocan Cameroon Fact Sheets: Breast Cancer. Lyon, France. http://globocan.iarc.fr/

[3] Hortobagyi, G.N., Salazar, J.G., Pritchard, K., et al. (2005) The Global Breast Cancer Burden: Variations in Epidemiology and Survival. Clinical Breast Cancer, 6, 391-401. http://dx.doi.org/10.3816/CBC.2005.n.043

[4] Porter, P. (2008) "Westernizing” Women's Risks? Breast Cancer in Lower-Income Countries. New England Journal of Medicine, 358, 213-216. http://dx.doi.org/10.1056/NEJMp0708307

[5] Walker, A.R.P., Adam, F.I. and Walker, B.F. (2014) Breast Cancer in Black African Women: A Changing Situation. Journal of the Royal Society of Health, 124, 81-85. http://dx.doi.org/10.1177/146642400412400212

[6] Vorobiof, D.A., Sitas, F. and Vorobiof, G. (2001) Breast Cancer Incidence in South Africa. Journal of Clinical Oncology, 19, 125s-127s.

[7] Anderson, O.B., Shyyan, R., Eniu, A., et al. (2006) Breast Cancer in Limited-Resource Countries: An Overview of the Breast Health Global Initiative 2005 Guidelines. The Breast Journal, 12, S3-S15. http://dx.doi.org/10.1111/j.1075-122X.2006.00199.x

[8] Sankaranarayanan, R., Swaminathan, R., Brenner, H., et al. (2010) Cancer Survival in Africa, Asia, and Central America: A Population-Based Study. The Lancet Oncology, 11, 165-173. http://dx.doi.org/10.1016/S1470-2045(09)70335-3

[9] Sankaranarayanan, R., Black, R.J., Swaminathan, R., et al. (1998) An Overview of Cancer Survival in Developing Countries. IARC Scientific Pubications, 145, 135-173.

[10] Bossard, N., Velten, M., Remontet, L., et al. (2007) Survival of Cancer Patients in France: A Population-Based Study from The Association of the French Cancer Registries (FRANCIM). European Journal of Cancer, 43, 149-160.

[11] American Cancer Society (2011) Breasts Cancer Facts Figures 2011-2012, Atlanta. American Cancer Society Inc. http://www.cancer.org/Research/CancerFactsfigures/BreastscancerFactsFigures/breast-cancer-facts-and-figures-2011-2 $\underline{012}$

[12] Ahmed, B. (2002) Pronostic du cancer du sein chez les femmes tunisiennes: Analyse d'une série hospitalière de 729 patientes. Santé Publique, 14, 231-241. http://dx.doi.org/10.3917/spub.023.0231

[13] Popoola, A.O., Ogunleye, O.O., Ibrahim, N.A., Omodele, F.O. and Igwilo, A.I. (2012) Five Year Survival of Patients with Breast Cancer at the Lagos State University Teaching Hospital, Nigeria. Online Journal of Medicine and Medical Science Research, 1, 24-31.

[14] Kemfang, J.D., Yomi, J., Kasia, J.M., Mawamba, Y., Ekortah, A.C. and Vlastos, G. (2011) Breast Cancer Profile in a Group of Patients Followed up at the Radiation Therapy Unit of the Yaounde General Hospital, Cameroon. Obstetrics and Gynecology International, 2011, Article ID: 143506.

[15] Terfa, S.K., Odigie, V.I., Yusufu, L., Bidemi, O., Sani, M.S. and Kase, J.J. (2010) Pattern of Presentation and Survival of Breast Cancer in a Teaching Hospital in North Western Nigeria. Oman Medical Journal, 25, 104-107. http://dx.doi.org/10.5001/omj.2010.29

[16] Anyanwu, S.N. (2000) Survival Following Treatment of Primary Breast Cancer in Eastern Nigeria. East African Medical Journal, 77, 539-543.

[17] Essiben, F., Foumane, P., Mboudou, E.T., Dohbit, J.S., Mve Koh, V. and Ndom, P. (2013) Diagnostic et traitement du cancer du sein au Cameroun. A propos de 65 cas. Mali Medical, 28, 38-42.

[18] Wilkinson, G.S., Edgerton, F., Wallace Jr., H.J., Reese, P., Patterson, J. and Priore, R. (1979) Delay, Stage of Disease and Survival from Breast Cancer. Journal of Chronic Disease, 32, 365-373. http://dx.doi.org/10.1016/0021-9681(79)90078-X

[19] Fowble, B.L., Schultz, D.J., Overmoyer, B., Solin, L.J., Fox, K., Jardines, L., et al. (1994) The Influence of Young Age on Outcome in Early Stage Breast Cancer. International Journal of Radiation Oncology*Biology*Physics, 30, 23-33. http://dx.doi.org/10.1016/0360-3016(94)90515-0

[20] Gobrane, H.B., Fakhfakh, R., Rahal, K., et al. (2007) Pronostic du cancer du sein à l'institut de carcinologique Salah Azaiez de Tunis. Eastern Mediteranean Health Journal, 13, 309-318.

[21] Wolters, R., Regierer, A.C., Schwentner, L., et al. (2012) A Comparison of International Breast Cancer GuidelinesDo the National Guidelines Differ in Treatment Recommendations? European Journal of Cancer, 48, 1-11. http://dx.doi.org/10.1016/j.ejca.2011.06.020

[22] Wöckel, A., Wolters, R., Wiegel, T., et al. (2014) The Impact of Adjuvant Radiotherapy on the Survival of Primary Breast Cancer Patients: A Retrospective Multicenter Cohort Study of 8935 Subjects. Annals of Oncology, 25, 628-632. http://dx.doi.org/10.1093/annonc/mdt584

[23] Whelan, T.J., Julian, J., Wright, J., Jadad, A.R. and Levine, M.L. (2000) Does Locoregional Radiation Therapy Im- 
prove Survival in Breast Cancer? A Meta-Analysis. Journal of Clinical Oncology, 18, 1220-1229.

[24] Fisher, B., Anderson, S., Bryant, J., et al. (2002) Twenty-Year Follow-Up of a Randomized Trial Comparing Total Mastectomy, Lumpectomy, and Lumpectomy Plus Irradiation for the Treatment of Invasive Breast Cancer. New England Journal of Medicine, 347, 1233-1241. http://dx.doi.org/10.1056/NEJMoa022152

[25] Veronesi, U., Cascinelli, N., Mariani, L., et al. (2002) Twenty-Year Follow-Up of a Randomized Study Comparing Breast-Conserving Surgery with Radical Mastectomy for Early Breast Cancer. New England Journal of Medicine, 347, 1227-1232. http://dx.doi.org/10.1056/NEJMoa020989 